\title{
Evaluating the cost utility of racecadotril for the treatment of acute watery diarrhea in children: the RAWD model
}

This article was published in the following Dove Press journal:

ClinicoEconomics and Outcomes Research

19 April 2012

Number of times this article has been viewed

\author{
Tamlyn Anne Rautenberg ${ }^{1,2}$ \\ Ute Zerwes' \\ Douglas Foerster ${ }^{3,4}$ \\ Rick Aultman ${ }^{5}$
}

'Assessment in Medicine $\mathrm{GmbH}$, Lörrach, Germany; ${ }^{2}$ Leeds Institute of Health Sciences, University of Leeds, Leeds, United Kingdom; ${ }^{3}$ Abbott Products Operations AG, Allschwil, Switzerland; ${ }^{4}$ University of Bielefeld, School of Public Health, Bielefeld, Germany; ${ }^{5}$ Semalytics, Arizona, United States of America
Correspondance: Tamlyn Anne Rautenberg

Marie Curie Str. 8, 79539,

Lörrach, Germany

Tel +49762I 70510500

Fax+49762I70510530

Email tamlyn.rautenberg@assessment-inmedicine.de
Background: The safety and efficacy of racecadotril to treat acute watery diarrhea (AWD) in children is well established, however its cost effectiveness for infants and children in Europe has not yet been determined.

Objective: To evaluate the cost utility of racecadotril adjuvant with oral rehydration solution (ORS) compared to ORS alone for the treatment of AWD in children younger than 5 years old. The analysis is performed from a United Kingdom National Health Service (NHS) perspective.

Methods: A decision tree model has been developed in Microsoft ${ }^{\circledR}$ Excel. The model is populated with the best available evidence. Deterministic and probabilistic sensitivity analyses (PSA) have been performed. Health effects are measured as quality-adjusted life years (QALYs) and the model output is cost $(2011 \mathrm{GBP})$ per QALY. The uncertainty in the primary outcome is explored by probabilistic analysis using 1000 iterations of a Monte Carlo simulation.

Results: Deterministic analysis results in a total incremental cost of $-£ 379$ in favor of racecadotril and a total incremental QALY gain in favor of racecadotril of +0.0008 . The observed cost savings with racecadotril arise from the reduction in primary care reconsultation and secondary referral. The difference in QALYs is largely attributable to the timely resolution of symptoms in the racecadotril arm. Racecadotril remains dominant when base case parameters are varied. Monte Carlo simulation and PSA confirm that racecadotril is the dominant treatment strategy and is almost certainly cost effective, under the central assumptions of the model, at a commonly used willingness to pay proxy threshold range of $£ 20,000-£ 30,000$ per QALY

Conclusion: Racecadotril as adjuvant therapy is more effective and less costly compared to ORS alone, from a UK payer perspective, for the treatment of children with acute diarrhea.

Keywords: cost effectiveness, health economic model, infant, QALY, racecadotril, acute watery diarrhea

\section{Introduction}

Despite advances in medicine over the last decades, acute watery diarrhea (AWD) remains the cause of substantial morbidity in developed countries. ${ }^{1}$ In England, approximately 150,000 children younger than 5 years old present with symptoms of vomiting and diarrhea (gastroenteritis) each year. In 2007-2008, approximately 37,000 children were admitted to secondary care hospitals. ${ }^{2}$ Oral rehydration solution (ORS) is the standard of care to replace fluid loss, but it has no impact on the duration or severity of diarrhea. There is limited availability of alternate therapies, especially those indicated for infants and children, which reduce the duration and severity of diarrhea. 
Racecadotril is a nonopiate enkephalinase inhibitor with a unique mechanism of action with rapid onset. ${ }^{3}$ The basally abundant enzyme enkephalinase degrades endogenous enkephalins in the intestinal mucosa that otherwise exhibit proabsorptive and antisecretory properties. Racecadotril prevents the degradation of enkephalins and thereby promotes antisecretion. ${ }^{4}$ Furthermore, it has no effect on intestinal motility and therefore no enteropooling or rebound constipation is experienced. There is also no respiratory depression or other central neurotoxicity effect, ${ }^{5-7}$ making this a favorable drug option, especially for children. ${ }^{4}$

Pediatric presentations of racecadotril were first authorized in France in 1999 and today it is approved and widely used in seven European countries (France, Spain, Italy, Portugal, Greece, Bulgaria, and Romania) and outside Europe. The efficacy of racecadotril has been well established in clinical studies and in an individual patient data meta-analysis. ${ }^{8-19}$ In addition, the safety of racecadotril in children has been demonstrated in clinical studies, including a large pre- and postaccess study showing that racecadotril has a favorable adverse event (AE) profile in children. ${ }^{9,12-14,19-21}$ Despite its proven safety and efficacy, the cost effectiveness of racecadotril for infants and children has not yet been determined in Europe. The objective of this analysis is to evaluate the cost effectiveness of racecadotril from a UK payer perspective.

\section{Evidence base}

A systematic literature search and review identified potential clinical studies and quality of life (QoL) and resource utilization data to populate the model. Focused literature searches have been performed in databases, including PubMed, Embase, and the Cochrane library. A detailed search strategy is available upon request. Available and relevant evidence has been weighed against each other to determine the highest quality for inclusion in the model.

\section{Model}

\section{Structure}

The Racecadotril in Acute Watery Diarrhea (RAWD) model is a decision tree programmed in Microsoft ${ }^{\circledR}$ Excel (Microsoft, Redmond, WA) and developed to evaluate the treatment of racecadotril as adjuvant to ORS (hereafter referred to only as racecadotril). The chosen comparator is ORS, which is the currently recommended treatment in the National Health Service (NHS) according to the National Institute for Health and Clinical Excellence (NICE). ${ }^{2}$ The model performs deterministic and probabilistic sensitivity analyses and considers costs and outcomes from the United Kingdom (UK) NHS perspective. Health effects are measured as quality-adjusted life years (QALYs) and the model output is cost (GBP) per QALY. The model uses a time horizon of 6 days based on the general assumption that nonsevere acute diarrhea is selflimiting to 6 days, and therefore no discounting is applied. According to the decision tree, children with symptoms of AWD present to primary care and are prescribed racecadotril or ORS alone. Forty-eight hours after the start of treatment, children with unresolved symptoms will reconsult at primary care, whereupon they may continue treatment as before, or if symptoms have worsened, they may be referred to secondary care. The face validity of this treatment pathway has been verified by two clinical experts ${ }^{22,23}$ and appears to agree with the literature reviewed and the management of diarrhea alluded to in the guidelines of the World Gastroenterology Organization, NICE, and the World Health Organization. ${ }^{1,2,24}$ The models' structure is illustrated in Figure 1.

\section{Base case parameters}

Clinical effectiveness data is available from ten individual studies, ${ }^{8-15}$ two systematic reviews, ${ }^{16,17}$ and two meta-analyses. ${ }^{18,19}$ The first systematic review, published in $2007,{ }^{16}$ includes three studies in the analysis. ${ }^{8,9,11}$ The results show that 48-hour stool output is significantly less in the racecadotril group than in the control group, with a standardized mean difference (SMD) of $-0.67 ; 95 \%$ confidence interval [CI] $(-0.9$ to -0.44$)$. The final outcome assessed is cure in 5 days or less, and pooled results show no significant difference between the racecadotril group and the control group (risk ratio [RR] 1.1; 95\% CI: 0.97 to 1.21). It can, however, be argued that this endpoint is flawed because all patients recovered by day five; the difference in recovery is significant around day two, as demonstrated by Lehert et al. ${ }^{19}$

The second systematic review, performed in 2008, ${ }^{17}$ includes two studies in the analysis. ${ }^{8,9}$ It shows that stool volume at 48 hours is less in the racecadotril group than in the control group (SMD $-0.65 ; 95 \% \mathrm{CI}$ : -0.88 to -0.42 ). Again, there is no difference in the proportion of children who recover by day five (RR $0.73 ; 95 \% \mathrm{CI}: 0.29$ to 1.81 ). ${ }^{17}$ Again, individual patient meta-analysis shows that the difference in recovery is significant around day two. ${ }^{19}$

The first meta-analysis ${ }^{18}$ includes four studies ${ }^{8,9,11,12}$ and shows a significant difference in stool output at 48 hours in favor of racecadotril $(P=0.00001) .{ }^{8,9}$ Heterogeneity between studies was not found statistically significant $(P=0.86$; $\left.\mathrm{I}^{2}=0 \%\right)$. The study also shows a statistically significant difference for children who revisited a pediatrician or emergency 


$\begin{array}{llll}\mathrm{T}_{0}(\mathrm{hrs}) & \mathrm{T}_{24} & \mathrm{~T}_{72} & \mathrm{~T}_{144} \\ \text { Diarrhea onset } & \text { Treatment starts } & \text { 48 hours after treatment start } & \text { Day } 6 \\ & & \text { Resolved or not resolved? } & \text { All resolved }\end{array}$

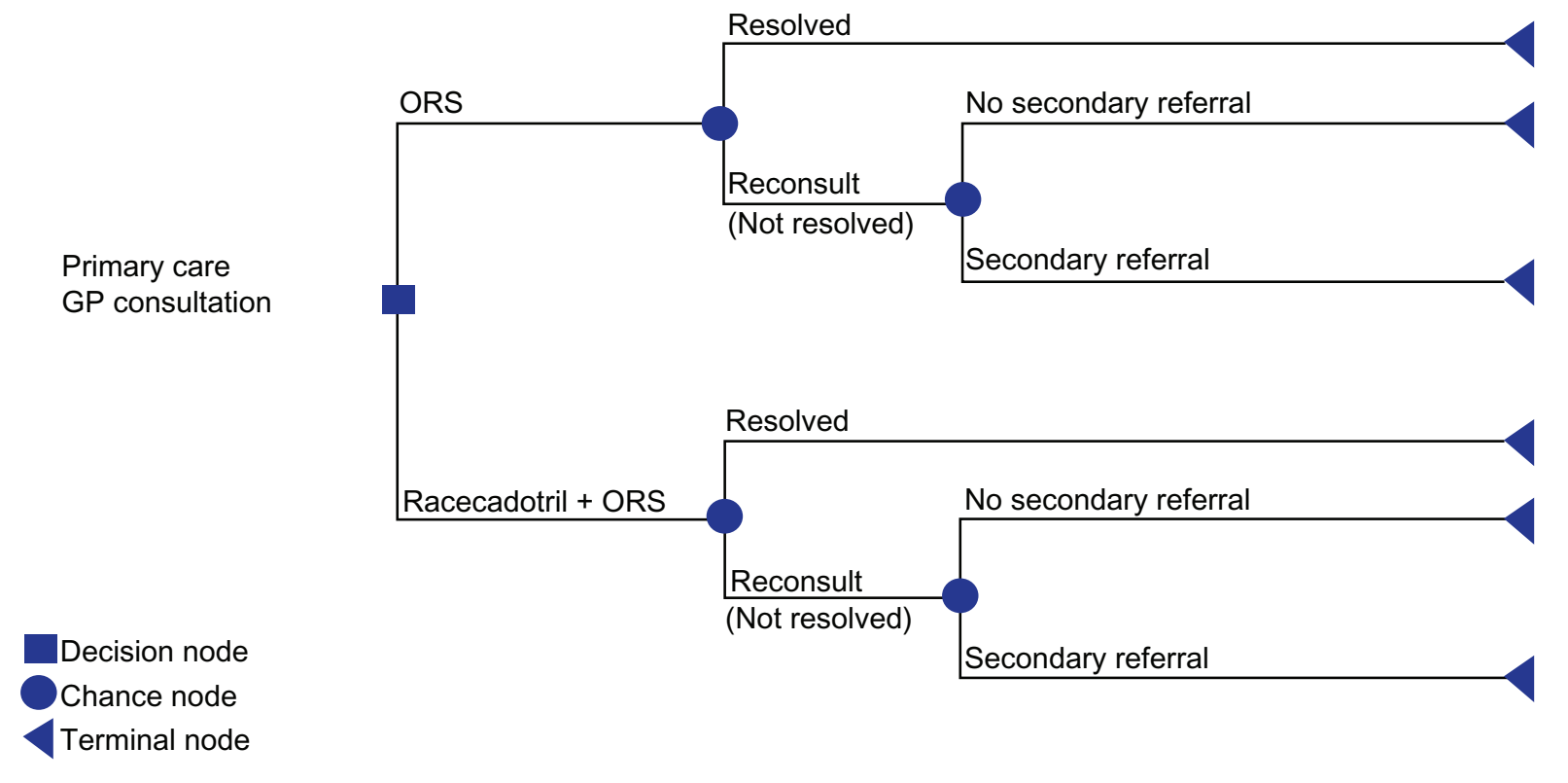

Figure I Decision tree model structure.

department 48 hours after treatment favoring racecadotril (RR $0.62 ; 95 \%$ CI: 0.40 to $0.97 ; P=0.04$ ) with homogeneity between studies $\left(P=0.41 ; \mathrm{I}^{2}=0 \%\right){ }^{11,12}$ The study further confirmed that racecadotril is comparable to ORS alone with respect to safety and tolerability. ${ }^{20}$

The second meta-analysis by Lehert et al includes nine studies (one publication reports two trials) s-15 $^{8}$ and aims to overcome the shortcomings of previous studies in general, which do not include all existing trials, estimate treatment effect using meta-analysis in literature, pool different endpoints, and do not explore the influence of baseline conditions on treatment effect (eg, dehydration level, rotavirus status, age, inpatient/outpatient setting, country). ${ }^{19}$ The study is an individual patient (raw data) meta-analysis that includes eight out of the ten available studies ${ }^{19}$ (one excluded study compares racecadotril to loperamide ${ }^{21}$ and the second was an open-label study that did not meet quality requirements). ${ }^{25}$ It is considered by the model developers to be the highest quality evidence and considers all relevant studies, including those with less favorable results for racecadotril, it is therefore used for the RAWD model. Results show that twice as many patients recover at any time with the racecadotril regimen: hazard ratio (HR) 2.04 (95\% CI: 1.85 to $2.32 ; P<0.001) .{ }^{19}$ To convert this to a proportion in the model, a Weibull distribution is fitted to the data and the proportional hazards assumption is used to vary the efficacy of the racecadotril arm with respect to the ORS arm. Using this distribution, the median for the racecadotril and ORS arms is reached at 1.75 and 2.79 days, respectively, and results in the reported HR at 2.75 days in agreement with the study data, which suggests a suitable fit. This distribution shows that after 48 hours of treatment, $58 \%$ and $26 \%$ of patients respond in the racecadotril and ORS arms, respectively. These results appear to correspond to the reductions in 48-hour stool volume and 48-hour stool output reported in other studies. ${ }^{16-19}$ As a conservative estimate, in the model it has been assumed that all children with unresolved symptoms at 48 hours reconsult their primary care facility.

A study by Cojocaru et al evaluated children presenting to an emergency department (A \& E) for diarrhea. ${ }^{11}$ Children were admitted for 24 hours at presentation and a scheduled visit on day 2 was included in the study protocol for all patients. Additional medical visits ( $>$ day $2 \leq$ day 7 ) were required for $34 \%$ of children in the ORS arm and $18 \%$ of children in the racecadotril arm $(P<0.05) .{ }^{11}$ Secondary referral was measured after day 2 . The details of this study do not typically represent the scenario modeled, which is the UK primary care setting; specifically, the model does not consider children presenting to A \& E instead of primary care for AWD. Only one study includes secondary referral data 
at 48 hours and demonstrates fewer hospital admissions for racecadotril compared to ORS at 24 hours $(P<0.005)$ and 48 hours $(P<0.0001)$; it has been included in the model. ${ }^{13}$

It is difficult to measure QoL in young children, however, there are three potentially relevant publications. In one, Huppertz et al analyzes parental perception of the impact of diarrhea on the QoL of their children. ${ }^{26}$ A second study evaluates the QoL in children with gastroenteritis in Canada. ${ }^{27}$ A third study rates the QoL of children with acute infectious gastroenteritis. ${ }^{28}$ In this study, two health state descriptions (for primary and secondary care) have been rated by general practitioners and pediatricians across five geographic areas in the UK. EuroQoL (EQ-5D) scores have been converted to utility values using UK population data and the time trade-off method. ${ }^{28}$ Secondary care ratings from general practitioners are more conservative than pediatricians and are therefore used in the model to calculate an average for children younger than 5 years old. It has been assumed that children with AWD have comparable QoL to those with acute infectious diarrhea; the same utility values have been used elsewhere for rotavirus infection. ${ }^{29}$ The Martin, Cottrell, and Standaert study is considered the highest quality and most relevant evidence because it includes EQ-5D data; it is based on UK population norms and utilizes the time trade-off approach and has therefore been used in the RAWD model. ${ }^{28}$

For the AE data, the following frequencies for racecadotril vs ORS are reported: $12.4 \%$ vs $16.2 \%,{ }^{20} 11.6 \%$ vs $10.1 \%,{ }^{19}$ $19.1 \%$ vs $20.2 \%,{ }^{12} 11.5 \%$ vs $22 \%$ (vs loperamide), ${ }^{21} 10 \%$ vs 7\% (vs placebo), ${ }^{9} 5 \%-6 \%$ (ORS arm not reported), ${ }^{14}$ and $6 \%$ (ORS arm not reported). ${ }^{13}$ The highest frequency of AEs comes from a study by Santos et al, involving 84 patients. ${ }^{12}$ By far the most extensive data comes from a pre-and postaccess analysis of individual case safety reports and clinical trial AEs from a total sample of 1129 records. ${ }^{20}$ The Baumer and Joulin study is based on the largest sample size and is comparable and/or conservative in comparison to the other estimates listed above; it is considered fair to include it as the highest quality evidence for the frequency of AEs in the model.

The drug cost is calculated at a dose of $1.5 \mathrm{mg}$ per kilogram $(\mathrm{kg})$ of body weight administered three times daily. The average weight of a child is assumed to be $13.5 \mathrm{~kg}$, based on an average estimate from multiple sources. ${ }^{30-33}$ ORS has been conservatively estimated to be administered after every stool in accordance with the definition of AWD, which states at least three watery stools are passed in 24 hours. ${ }^{1}$ The weighted average cost of an ORS sachet is calculated at $£ 0.29$ per sachet, at a total daily cost of $£ 0.88 .{ }^{34}$ The drug cost of racecadotril is $£ 0.42$ per $10 \mathrm{mg}$ sachet $^{35}$, resulting in a total daily drug cost of $£ 3.82$ (including ORS).

The national average cost of a primary care consultation of $£ 36$ (based on an 11.7 minute consultation) and the national average cost of secondary care for a nonelective short inpatient stay of $£ 523$ are used in the model. ${ }^{36}$ Hospital Episode Statistics for England (Inpatient) 2010-2011 are used to estimate the average length of stay for deterministic analysis. ${ }^{37}$ Hospital Resource Group 4 (HRG4) and ICD-10 ${ }^{38}$ data are shown in Table 3. The value of 2.65 days ( 3 days) is used for deterministic analysis based on the average of ICD-10 A00-A09 (intestinal infectious diseases) and HRG4 PA21B (infectious and noninfectious gastroenteritis without complications and comorbidities) codes, those being the only codes with actual numbers of children recorded in the relevant age group (number of children aged 0-14 years: 37,889 for PA21B; 29,689 for A00-A09). ${ }^{37,38}$

For AEs, Baumer and Joulin report the most common AE to be vomiting (5.1\% vs 5.8\%), fever (2.3\% vs $4.6 \%$ ), and allergic AEs (1.3\% vs 4.1\%) for racecadotril and ORS, respectively. ${ }^{20}$ Half of all AEs reported by individual case safety reports are classified as "skin and subcutaneous tissue disorders", which are mainly rash and urticaria. ${ }^{20}$ In the absence of available AE cost data, an average weighted cost for vomiting (£15), allergic AEs (£20), and fever ( $£ 50$ ) is used in the model. A summary of the model parameters is shown in Table 1.

\section{Model assumptions}

The RAWD model assumes that children presenting with clinical dehydration at the first primary care consultation are referred immediately to secondary care in accordance with current clinical practice guidelines and are not included in the modeled population. ${ }^{2}$ The treatment effect in the model is irrespective of diarrhea duration prior to the first primary care consultation and etiology of diarrhea. Also in accordance with practice guidelines and confirmed by experts in primary care, stool sampling is not routine practice and is not included in the model. ${ }^{22,23}$ It is assumed that when symptoms of AWD resolve, the treatment stops and the daily drug cost is no longer incurred. Furthermore, if diarrhea has not resolved at first and second primary care consultations, and if there is no secondary referral, the diarrhea will be self-limiting and resolve at day 6 (maximum treatment duration, 6 days). The model considers the drug cost of actual sachets used for each regimen and does not include the effects of wastage or compliance. 
Table I Base case parameters

\begin{tabular}{|c|c|c|c|}
\hline Base case parameter & Deterministic value & Probabilistic distribution & Source \\
\hline \multicolumn{4}{|l|}{ Primary care } \\
\hline Proportion resolving at 48 hours* ORS & $26 \%$ & Weibull & Lehert et al ${ }^{19}$ \\
\hline Proportion resolving at 48 hours $R+$ ORS & $58 \%$ & Weibull & Lehert et al ${ }^{19}$ \\
\hline \multicolumn{4}{|l|}{ Secondary care } \\
\hline Secondary referral at 48 hours ORS & $36 \%$ & Beta & Alvarez Calatayud et al ${ }^{13}$ \\
\hline Secondary referral at 48 hours $R+$ ORS & $6 \%$ & Beta & Alvarez Calatayud et $\mathrm{a}^{13}$ \\
\hline \multicolumn{4}{|l|}{ AEs } \\
\hline Frequency of $A E$ ORS & $16 \%$ & Beta & Baumer and Joulin ${ }^{20}$ \\
\hline Frequency of $A E R+O R S$ & $12 \%$ & Beta & Baumer and Joulin ${ }^{20}$ \\
\hline \multicolumn{4}{|l|}{ Quality of life } \\
\hline Average QoL $\mathrm{PC}<5$ years & 0.7345 & Beta & Martin et $\mathrm{a}^{28}$ \\
\hline Average QoL SC $<5$ years & 0.6145 & Beta & Martin et $\mathrm{al}^{28}$ \\
\hline
\end{tabular}

Note: $* 48$ hours from start of treatment.

Abbreviations: ORS, oral rehydration solution; R, racecadotril; AE, adverse events; QoL, quality of life; PC, primary care; SC, secondary care.

\section{Results}

The deterministic analysis calculates the cost and benefits over a six-day time horizon. The total drug cost for racecadotril vs ORS is $£ 12.17$ vs $£ 3.03$, primary care costs are $£ 51.12$ vs $£ 62.64$, secondary care costs are $£ 40.20$ vs $£ 416.82$, and AEs cost $£ 0.35$ vs $£ 0.46$ per patient. The total average cost for racecadotril and ORS treatment regimens is $£ 103.84$ vs $£ 482.95$, respectively. The most notable cost savings with racecadotril arises from the reduction in secondary care costs. The cost comparison data is summarized in Table 2 . The total incremental cost is $-£ 379$ in favor of racecadotril. The total incremental QALY gain in favor of racecadotril is +0.0008 for a 6-day period. The difference in QALYs is largely attributable to the timely resolution of symptoms in the racecadotril arm. The incremental cost effectiveness ratio is $-£ 473,750$ with racecadotril being the dominant treatment strategy, which means that racecadotril (adjuvant) is more efficacious and less costly than ORS alone under the central assumptions of the model.

\section{Uncertainty}

For the deterministic analysis, when the "average length of stay for secondary care" is reduced from three to one night, the incremental cost is $-£ 128$ and the incremental QALY gain is +0.0016 , resulting in a dominant incremental cost effectiveness ratio of $-£ 80,000$ in favor of racecadotril.

Table 2 Cost comparison results (deterministic)

\begin{tabular}{lll}
\hline Cost results & ORS & Racecadotril + ORS \\
\hline Drug cost & $£ 3.03$ & $£ 12.17$ \\
Primary care & $£ 62.64$ & $£ 51.12$ \\
Secondary care & $£ 416.82$ & $£ 40.20$ \\
Adverse events & $£ 0.46$ & $£ 0.35$ \\
Total mean cost per patient & $£ 482.95$ & $£ 103.84$ \\
\hline
\end{tabular}

For AEs, when the least favorable estimate ${ }^{12}$ is entered for both regimens, the resultant incremental cost effectiveness ratio is $-£ 494,830 .{ }^{12}$ When both parameters (LOS and $\mathrm{AE}$ ) are varied simultaneously, the result is $-£ 81,885$, with racecadotril remaining the dominant treatment strategy. Varying deterministic base case estimates by $20 \%$ (constrained by maximum and minimum values) shows that the model is most sensitive to the QoL estimate of a "well" person. The value is taken from a UK national survey commissioned by the Department of Health and published as a working paper by the Centre for Health Economics, York University. ${ }^{39} \mathrm{~A}$ total of 3395 adults in the UK were interviewed using the EQ-5D. ${ }^{39}$ The base case value of 0.94 was used, which is the mean for those aged under 25 years and is the closest approximation to a child's full health that is available, to the best of the model developers' knowledge.

To evaluate the uncertainty in the parameter estimates, a probabilistic sensitivity analysis has been performed by fitting distributions (shown in Table 1) to the deterministic estimates and running 1000 iterations of a Monte Carlo simulation. Probabilistic sensitivity analysis shows that racecadotril is the dominant treatment strategy, it being less costly and more effective compared to ORS alone, as shown in Figure 2. The cost effectiveness acceptability curve shows that the racecadotril strategy is almost certainly cost effective at a proxy willingness-to-pay threshold range of $£ 20,000-£ 30,000$ per QALY.

\section{Discussion}

This model has been developed from a UK perspective and all cost and utility data are derived from British sources. The reader should consider that the available studies for the other base case parameters originate from Europe (three from France $^{8,11,21}$ [one study vs loperamide] and two from Spain ${ }^{12,13}$ ) 
Table 3 HRG4 and ICD-I0 data for length of stay

\begin{tabular}{|c|c|c|c|}
\hline Code & Description & $\begin{array}{l}\text { Age } \\
0-14 \text { years* }\end{array}$ & $\begin{array}{l}\text { Mean } \\
\text { LOS }\end{array}$ \\
\hline \multicolumn{4}{|l|}{ HRG4 } \\
\hline FZ36C & $\begin{array}{l}\text { Intestinal infectious disorders } \\
\text { without cc }\end{array}$ & 0 & 4.5 \\
\hline FZ36E & $\begin{array}{l}\text { Intestinal infectious disorders } \\
\text { with length of stay I day } \\
\text { or more without major cc }\end{array}$ & 0 & 4.4 \\
\hline $\mathrm{FZ36F}$ & $\begin{array}{l}\text { Intestinal infectious disorders } \\
\text { with length of stay } 0 \text { days }\end{array}$ & 0 & 0.4 \\
\hline PA2IB & $\begin{array}{l}\text { Infectious and noninfectious } \\
\text { gastroenteritis without cc }\end{array}$ & 37889 & 0.7 \\
\hline WA06Y & Other viral illness without cc & 0 & 1.5 \\
\hline \multicolumn{4}{|c|}{ ICD-I 0 (primary diagnosis summary) } \\
\hline $\mathrm{A} 00-\mathrm{A} 09^{\dagger}$ & Intestinal infectious diseases & 29689 & 4.6 \\
\hline $\begin{array}{l}\text { Notes: } * \mathrm{Nu} \\
\text { were up to } \\
\text { inflammatory } \\
\text { gastroenterit }\end{array}$ & $\begin{array}{l}r \text { of finished consultant episodes } \\
\text { ears of age (inclusive) when the e } \\
\text { rrhea - bacterial cause (A04), vi } \\
\text { d colitis, unspecified (A09). }{ }^{37,38}\end{array}$ & $\begin{array}{l}\text { E) relating to } p \\
\text { de began; tinclu } \\
\text { zause (A06), an }\end{array}$ & $\begin{array}{l}\text { nts who } \\
\text { infantile } \\
\text { fectious }\end{array}$ \\
\hline Abbreviatic & cc, complications and comorbiditie & OS, length of st & \\
\hline
\end{tabular}

and the rest of the world (Mexico, ${ }^{14}$ Guatemala, ${ }^{15}$ India, ${ }^{10}$ and Peru $\left.^{9}\right)$. It is generally accepted that the five European studies are more closely representative of the UK health care system. Differences for the rest of the world studies are most likely to arise from differences in resource utilization, assuming that children in developing countries are more likely to have underlying conditions that predispose them to more severe diarrhea and more potential for clinical dehydration (eg, malnutrition, etc) and referral. No resource utilization (reconsultation and referral) data from the rest of world studies is used in the model.

The population modeled in this analysis is infants and children younger than 5 years old. Regarding clinical efficacy, the Lehert et al meta-analysis included nine studies for the determination of diarrhea duration (one study had two sets of results). ${ }^{19}$ The maximum age in all studies is 5 years (60 months), except in the Melendez Garcia study, which is 71 months. ${ }^{15}$ The authors note that results are similar for infants aged under 1 year old $(\mathrm{n}=714$; HR 2.01; $95 \%$ CI: $1.71-2.36 ; P<0.001)$ and toddlers aged over 1 year old ( $=670$; HR 2.16; 95\% CI: 1.83-2.57; $P<0.001$ ). The heterogeneity among studies is small $\left(\mathrm{I}^{2}=0.28\right) .{ }^{19}$ The QoL data from the Martin, Cottrell, and Standaert study includes separate scores for children under 18 months old and 18 month to 5 year olds. ${ }^{28}$ Raw scores have been modified to account for inability to rate mobility and self-care in very young children. An average utility for both age groups has been calculated and used in the model. ${ }^{28}$ For AEs, the Baumer and Joulin study does not specify the age range for the data included; however, the authors note that the nature and frequency of AEs does not differ significantly between children aged under 30 months and older children. ${ }^{20}$ It therefore seems reasonable to assess the impact of AWD in children younger than 5 years old as a group.

In 2009, NICE issued guidance for vomiting and diarrhea in children younger than 5 years old. ${ }^{2}$ The supplementary costing

Probabilistic senstivity analysis - Monte Carlo simulation 1000 iterations

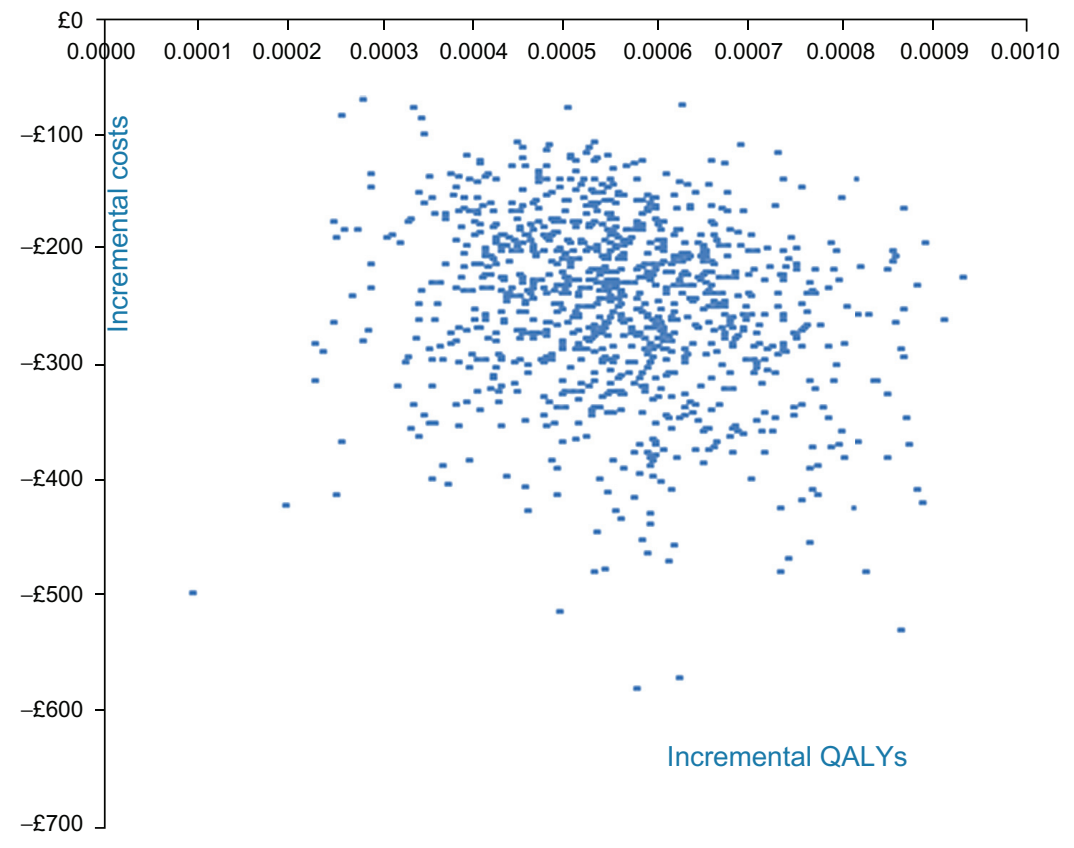

Figure 2 Probabilistic sensitivity analysis results. 
statement predicts that implementation of the clinical practice guideline is not likely to have significant savings at the national level. ${ }^{40}$ In view of the evidence available at that time, this is a reasonable assessment; however, in the light of new evidence, there seems to be opportunity for substantial cost savings. The model shows that the first cost driver for diarrhea in the under-5 age group is the reconsultation rate for primary care (not including dehydration). For the UK, this is confirmed by experts, who report reconsultation rates as high as $30 \%,{ }^{23}$ with recent results from Cegedim indicating a $14.3 \%$ reconsultation rate in children 4 years old and younger. ${ }^{41}$ As described, studies generally measure efficacy using stool output/48 hours, number of diarrheic stools, stool volume, and diarrhea duration. The most clinically and economically meaningful result seems to be diarrhea duration, as this has a direct influence on the reconsultation rate for children with unresolved symptoms and affects the QoL of children and their caregivers. By resolving the symptoms of diarrhea within 48 hours, the reconsultation rate can potentially be reduced, with resultant cost savings. The second cost driver identified is the secondary care admission rate, which not only contributes to cost but adds the risk of nosocomial infection. ${ }^{42}$ Again, by timely resolution of diarrhea and avoidance of secondary referral costs, the burden of resource utilization is alleviated. Furthermore, the model assumes a constant secondary referral rate over time; however, it may be that as the duration of diarrhea increases, the rate of secondary referral increases accordingly. This hypothesis is not extensively explored in the current literature and may be a useful question for future research. If a differential secondary referral rate is proven, then the full benefit of racecadotril shortening disease duration in comparison to ORS alone ${ }^{19}$ is underestimated in the RAWD model. A further contributor to cost, which also has not been included in the model, arises from the impact of diarrhea in children on their parents and caregivers. Van der Wielen et al sampled 1102 parents of children younger than 5 years old seeking medical care as a result of acute gastroenteritis. The proportion requiring at least one person to be absent from work was 20\%-64\% for primary care setting and $39 \%-91 \%$ for secondary care setting. ${ }^{43}$ From a broader societal perspective, the cost of children's AWD is therefore likely to be much higher than from a payer's perspective.

\section{Conclusion}

The RAWD model demonstrates that, considering the best available evidence, racecadotril is cost effective in the treatment of AWD in children. The model highlights the potential cost savings arising from reduction in diarrhea duration and avoidance of reconsultation and referral rates in children with diarrhea.

\section{Acknowledgments/disclosures}

Doctor Lisa Silver and Doctor Sarah Hall provided expert opinion from the UK NHS. Ute Zerwes and Christoph Schmidt performed literature searches in addition to Tamlyn Rautenberg. Kurt Banz from Outcomes International performed independent external model validation. Rick Aultman provided independent statistical consultation and validation with no compensation from any party. Douglas Foerster is employed by Abbott. The model development was sponsored by Abbott. No medical writing services have been used in the production of this manuscript.

\section{References}

1. World Gastroenterology Organisation (WGO). World Gastroenterology Organisation practice guideline: Acute diarrhea. 2008. Available from: http://www.omge.org/assets/downloads/en/pdf/guidelines/01_acute_ diarrhea.pdf. Accessed on August 12, 2011.

2. National Collaborating Centre for Women's and Children's Health (NCCWCH). Diarrhoea and vomiting diagnosis, assessment and management in children younger than 5 years caused by gastroenteritis. 2009 .

3. Lecomte JM. An overview of clinical studies with racecadotril in adults. Int J Antimicrob Agents. 2000;14(1):81-87.

4. Farthing MJ. Antisecretory drugs for diarrheal disease. Dig Dis. 2006; 24(1-2):47-58.

5. Spillantini MG, Geppetti P, Fanciullacci M, Michelacci S, Lecomte JM, Sicuteri F. In vivo 'enkephalinase' inhibition by acetorphan in human plasma and CSF. Eur J Pharmacol. 1986;125(1):147-150.

6. Knisely JS, Beardsley PM, Aceto MD, Balster RL, Harris LS Assessment of the abuse potential of acetorphan, an enkephalinase inhibitor. Drug Alcohol Depend. 1989;23(2):143-151.

7. Duval-Iflah Y, Berard H, Baumer P, et al. Effects of racecadotril and loperamide on bacterial proliferation and on the central nervous system of the newborn gnotobiotic piglet. Aliment Pharmacol Ther. 1999; 13(Suppl 6):9-14.

8. Cezard JP, Duhamel JF, Meyer M, et al. Efficacy and tolerability of racecadotril in acute diarrhea in children. Gastroenterology. 2001;120(4): 799-805.

9. Salazar-Lindo E, Santisteban-Ponce J, Chea-Woo E, Gutierrez M. Racecadotril in the treatment of acute watery diarrhea in children. N Engl J Med. 2000;343(7):463-467.

10. Savita MR, Mysore GMC. Racecadotril - a novel drug for the treatment of acute watery diarrhea in Indian children. 2nd Pediatric Infectious Diseases Conference 2006. Available from: http://www.pediatriconcall. com/fordoctor/conference_abstracts/racecadotrial.asp. Accessed on September 2, 2011.

11. Cojocaru B, Bocquet N, Timsit S, et al. Effect of racecadotril in the management of acute diarrhea in infants and children. Arch Pediatr. 2002;9(8):774-779.

12. Santos M, Maranon R, Miguez C, Vazquez P, Sanchez C. Use of racecadotril as outpatient treatment for acute gastroenteritis: a prospective, randomized, parallel study. J Pediatr. 2009;155(1):62-67.

13. Alvarez Calatayud E, Pinei Simon G, Taboada Castro L, et al. Efectividad de racecadotrilo en el tratamiento de la gastroenteritis aguda [The effectiveness of racecadotril in the treatment of acute gastroenteritis.]. Acta Pediatr Esp. 2009;67(3):117-122. 
14. Gutierrez-Castrellon P, Acosta-Bastidas M, Llamosas Gallardo B, et al. Ensayo clinico aleatorizado y analisis farmacoeconomico del impacto de racecadotrilo (Hidrasec) como coadyuvante en el tratamiento de la gastroenetritis aguda sobre la reduccion de los gastos hospitalierios relacionados en lactantes menores de 24 meses en Mexico. Rev Invest Clin. 2011. In press.

15. Melendez Garcia JM, Rodriguez JT. Racecadotril en el tratamiento de la diarrea agudo en ninos. Rev Facultad Med (Guatemala). 2007;4: 25-28.

16. Szajewska H, Ruszczynski M, Chmielewska A, Wieczorek J. Systematic review: racecadotril in the treatment of acute diarrhoea in children. Aliment Pharmacol Ther. 2007;26(6):807-813.

17. Emparanza Knörr JI, Ozcoidi Erro I, Martínez Andueza MC, Callén Blecua MT, Alústiza Martínez E, Aseguinolaza Iparraguirre I. Revisión sistemática sobre la eficacia de racecadotrilo en el tratamiento de la diarrea aguda [Systematic review of the efficacy of racecadotril in the treatment of acute diarrhea.] An Pediatr (Barc). 2008;69(5): $432-438$.

18. Hao R, De Vera M, Resurreccion E. Racecadotril in the treatment of acute diarrhea in children: a meta-analysis. PIDSP Journal 2010;11(2): 19-32.

19. Lehert P, Cheron G, Calatayud GA, et al. Racecadotril for childhood gastroenteritis: an individual patient data meta-analysis. Dig Liver Dis. 2011;43(9):707-713.

20. Baumer P, Joulin Y. Pre- and postmarketing safety profiles of Racecadotril sachets, a "new" antidiarrhoeal drug. J Pediatr Gastroenterol Nutr. 2009;48(Suppl 3):E99.

21. Turck D, Berard H, Fretault N, Lecomte JM. Comparison of racecadotril and loperamide in children with acute diarrhoea. Aliment Pharmacol Ther. 1999;13(Suppl 6):27-32.

22. Hall S. Expert Interview Primary Care Physician United Kingdom. 13-11-2012.

23. Silver L. Expert Interview Primary Care Physician United Kingdom. 13-12-2011.

24. World Health Organization (WHO). The treatment of diarrhoea A manual for physicians and other senior health workers. 2005. Available from: http://www.who.int/maternal_child_adolescent/ documents/9241593180/en/. Accessed on February 16, 2012.

25. Chacon J. Analysis of factors influencing the overall effect of racecadotril on childhood acute diarrhea. Results from a real-world and post-authorization surveillance study in Venezuela. Ther Clin Risk Manag. 2010;6:293-299.

26. Huppertz HI, Forster J, Heininger U, Roos R, Neumann HU, Hammerschmidt T. The parental appraisal of the morbidity of diarrhea in infants and toddlers (PAMODI) survey. Clin Pediatr (Phila). 2008;47(4): 363-371.
27. Brisson M, Senecal M, Drolet M, Mansi JA. Health-related quality of life lost to rotavirus-associated gastroenteritis in children and their parents: a Canadian prospective study. Pediatr Infect Dis J. 2010;29(1):73-75.

28. Martin A, Cottrell S, Standaert B. Estimating utility scores in young children with acute rotavirus gastroenteritis in the UK. J Med Econ. 2008;11(3):471-484

29. Goossens LM, Standaert B, Hartwig N, Hovels AM, Al MJ. The cost-utility of rotavirus vaccination with Rotarix (RIX4414) in the Netherlands. Vaccine. 2008;26(8):1118-1127.

30. World Health Organization (WHO). The WHO Child Growth Standards. 2012. Available from: http://www.who.int/childgrowth/en/. Accessed on February 16, 2012.

31. Buzzle com. Average Weight for Children by Age. 2012. Available from: http://www.buzzle.com/articles/average-weight-for-childrenby-age.html. Accessed on February 16, 2012.

32. Royal College of Paediatrics and Child Health (RCPCH). UK-WHO growth charts. 2012. Available from: http://www.rcpch.ac.uk/Research/ UK-WHO-Growth-Charts. Accessed on February 16, 2012.

33. World Health Organization (WHO). Growth reference data for 5-19 years. 2012. Available from: http://www.who.int/growthref/en/. Accessed on February 16, 2012.

34. Joint Formulary Committee. British National Formulary; 2008.

35. Abbott Products Operations AG. United Kingdom Drug Cost Estimate. 2012.

36. Personal Social Services Research Unit. Unit Costs of Health and Social Care 2010 PSSRU. Personal Social Services Research Unit Kent; 2010.

37. Primary diagnosis: summary. Hospital Episodes Statistics - HESonline 2012; Available from: http://www.hesonline.nhs.uk/Ease/servlet/Con tentServer?siteID=1937\&categoryID=202. Accessed on February 16, 2012.

38. Healthcare Resource Groups. Hospital Episodes Statistics - HESonline 2012. Available from: URL: http://www.hesonline.nhs.uk/Ease/servlet/ ContentServer?siteID =1937\&categoryID=206. Accessed on February 16, 2012.

39. Kind P, Hardman G, Macran S. UK Population Norms for EQ-5D, Discussion Paper 172. Centre for Health Economics York University; 1999.

40. National Institute for Health and Clinical Excellence (NICE). Costing statement: diarrhoea and vomiting in children; 2009.

41. Cegedim Strategic Data UK Limited. Cegedim Strategic Data; 2011

42. Koletzko S, Osterrieder S. Acute infectious diarrhea in children. Dtsch Arztebl Int. 2009;106(33):539-547.

43. Van der Wielen M, Giaquinto C, Gothefors L, et al. Impact of community-acquired paediatric rotavirus gastroenteritis on family life: data from the REVEAL study. BMC Fam Pract. 2010;11:22.
ClinicoEconomics and Outcomes Research

\section{Publish your work in this journal}

ClinicoEconomics \& Outcomes Research is an international, peerreviewed open-access journal focusing on Health Technology Assessment, Pharmacoeconomics and Outcomes Research in the areas of diagnosis, medical devices, and clinical, surgical and pharmacological intervention. The economic impact of health policy and health systems

\section{Dovepress}

organization also constitute important areas of coverage. The manuscript management system is completely online and includes a very quick and fair peer-review system, which is all easy to use. Visit http://www.dovepress.com/testimonials.php to read real quotes from published authors. 